\title{
Control and regulation systems of energy networks in buildings
}

\author{
Zuzana Kolková ${ }^{1, *}$, Peter Hrabovský ${ }^{1}$, Jozef Matušov ${ }^{1}$, Martina $^{1}$ Antošová and Michal \\ Holubčík ${ }^{2}$ \\ ${ }^{1}$ University of Žilina, Research centre, Univerzitná 8215/1, 01026 Žilina, Slovakia \\ ${ }^{2}$ University of Žilina, Department of Power Energy, Univerzitná 8215/1, 01026 Žilina, Slovakia
}

\begin{abstract}
Measurement, regulation and control systems offer direct savings and reduce energy consumption, regulating heating, cooling, ventilation or lighting in the intelligent buildings. They provide quick and accurate information on the status of regulated systems or possible malfunction. Systems can use the special meteorological stations to get information about wind velocity and direction, outdoor temperature, intensity and direction of sunlight. They respond flexibly to changes in external parameters. Intelligent buildings combine architecture and aesthetics of the construction, safety, comfort and quality of the living. These buildings are productive, energy efficient and environmentally acceptable. Intelligent buildings combine internal and external intelligence building, intelligence used materials and constructions. The most important aspect is the cooperation of people with those systems. Intelligent buildings should be permanent, healthy, technologically advanced.
\end{abstract}

\section{Introduction}

The intelligent building control is based on communication with all embedded system devices in the form of data messages sent by the data cable. Sensors, thermostats, motion sensors, fire detectors are designed to monitor the situation and then send the measured data bus. The bus will send a command that accepts and executes the requested operation. Dimmers, binary outputs, power switches are among the actuators. Changes to the control system or its deployment can be realized without the necessity of reworking the project or installing new cables. Changes to an existing system can be made after several years [1].

Communication between the devices involved in the control system with each other and with the control system ensures its proper functioning. This connection can be secured by cable or wireless. The benefits of cable connection include high speed, cost and availability of the devices needed for the connection. It is the most used connection because of the connection of electrical equipment to the devices $[2,3]$.

Intelligent buildings should be permanent, healthy, technologically advanced. They should meet the requirements and needs of the people and should be flexible to the changes you want. The role of intelligent buildings is also using its built-in system to create

\footnotetext{
*Corresponding author: zuzana.kolkova@rc.uniza.sk
} 
high-quality internal and external environment while meeting environmental and effective values. This means that the design, construction, technical equipment and building management should be on one level. The most important aspect is the cooperation of people with these systems. System thinking is necessary in the design and management of buildings with the talent that create, innovate and remain mostly practical and is always focused on maximum simplicity. The most important function of the building is to create a suitable environment for humans $[4,5,6]$.

\section{Energy systems}

Heating and cooling are used to create thermal comfort in the building. For its function using thermal and cold heat sources, which are mostly electric heat pumps ground - water, air - water and gas heat pump air - water (Figure 1.). The main objective is to understand the functioning of all intelligent building systems and ensure optimal use of all energy sources.
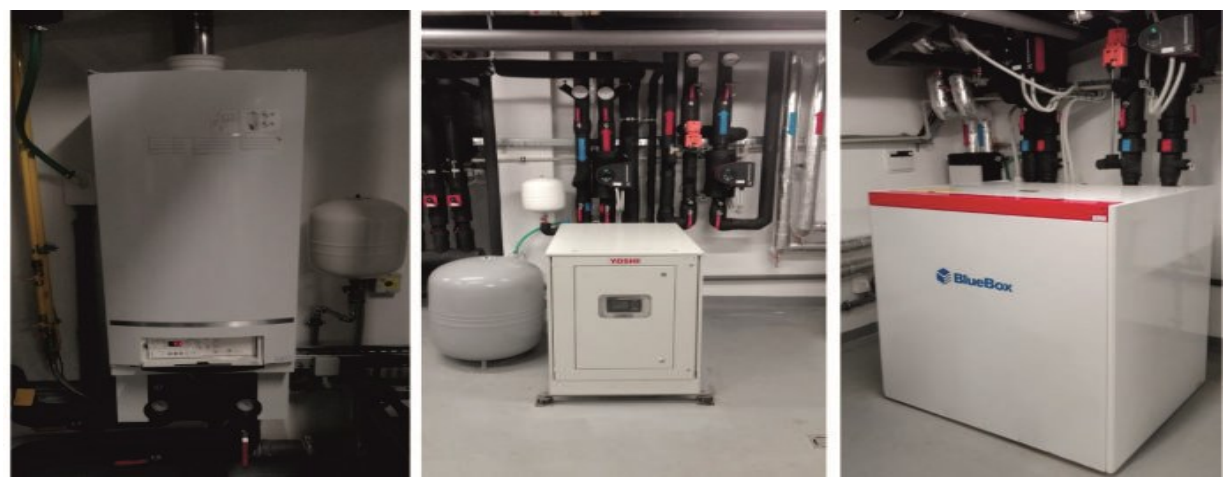

Fig. 1. Gas and electric heat pumps, gas boiler.

Heat pumps use heat from the environment either through boreholes from the ground or from the air. The intelligent building has 10 boreholes. Each borehole has 100 meters. Heat can also earn seasonal rooftop solar tube collectors. In the extreme case is used gas boiler. Cold is obtained directly from boreholes. If this is not enough, system can use chillers on the roof. In the future, the heat source will be used a natural heat storage. Heat and cold are distributed as needed to the building from the utility room in the basement. Distribution is ensured by controlling heating and cooling branches. Areas of the buildings are supplied with a hot and cold individual with a room-based accuracy based on user requirements. Set temperature can be changed directly in the room $\pm 3{ }^{\circ} \mathrm{C}$ or centrally via building management. Technological elements of heating and cooling are managed centrally at the resources. Boreholes are closed independently, thus it is possible to change their order and count in the required pumping capacity cold around $8{ }^{\circ} \mathrm{C}$ or heat through the heat pump (water-glycol media). Research centre areas of the building are in normal operation priority supplied heat through underfloor heating and cooled ceilings.

Cooling and heating are possible in all the settings for research purposes. Section of the light and blinds is also used to create thermal comfort of people in the building. LED light sources are used, part is bionic. Blinds eliminate excessive dazzle in conjunction with lighting. The desired light intensity can be adjusted separately for each room. Lighting in hallways and bathroom is automatic. Classical switches are also used in technical premises (Figure 2). Section of ventilation and air conditioning provides ventilation in the building. Three air handling units (on the roof) using for this function. Regulation is centralized and 
automated. It is possible to control the flaps to the nearest room. Ventilation in sanitary facilities is an automatic under pressure.

Cooling of server rooms and DAT Centre is independent and automatic (5 units). Through central control and monitoring intelligent building can monitor and control individual components collect data in real time and from a database. It serves as a support for projects and research tasks. Management is based on software tools that are an extension of the management processes of the building. Point of contact is a SCADA or OPC server. Display information about experiments, availability of equipment, laboratories are located in front of each room.

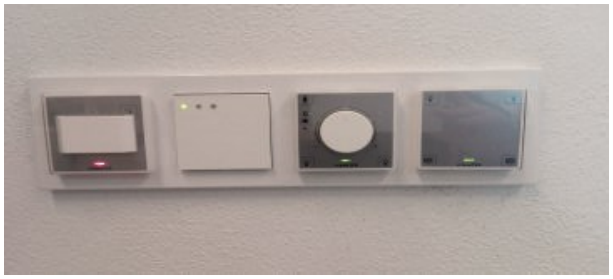

Fig. 2. Humidity sensor, $\mathrm{CO}_{2}$ sensor, regulator of lighting, temperature and blinds.

Additional technologies include elements built into the construction of buildings. Pressure, temperature, humidity, radiation and wind speed are part of these technologies. Intelligent building have also camera system, sensor of lighting in the room and the presence of persons in the building, fire detector FES, fire button FES, and fire alarm FES.

\section{Control system}

Control system of intelligent building should reduce building energy and maintenance costs compared to a non-controlled building. A demonstration of the control of one floor is shown in Figure 3.

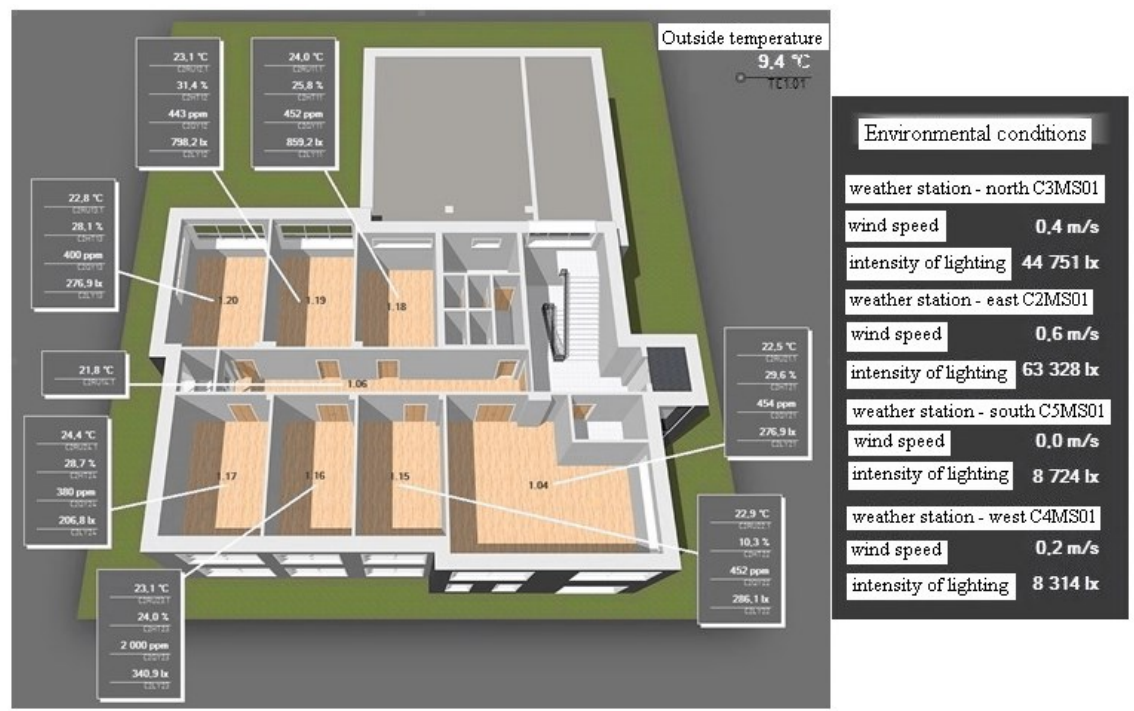

Fig. 3. Control system for one floor.

Central management programs run on internal servers and workstations of the university, data repositories, and in an internally doubled separated LAN network with a connection to the external communication and computing infrastructure of the school. 
The system is controlled through the BACnet (Building Automation Control Network) open communication standard. Regulators and automation stations communicate with this interface. External environmental conditions are recorded by the weather station, which is located on the building. It is possible to set individual parameters for each room individually or for one floor or for the whole building.

The systems for heating, ventilation, cooling and heating of hot water are controlled in the technical room according to Figure 4.

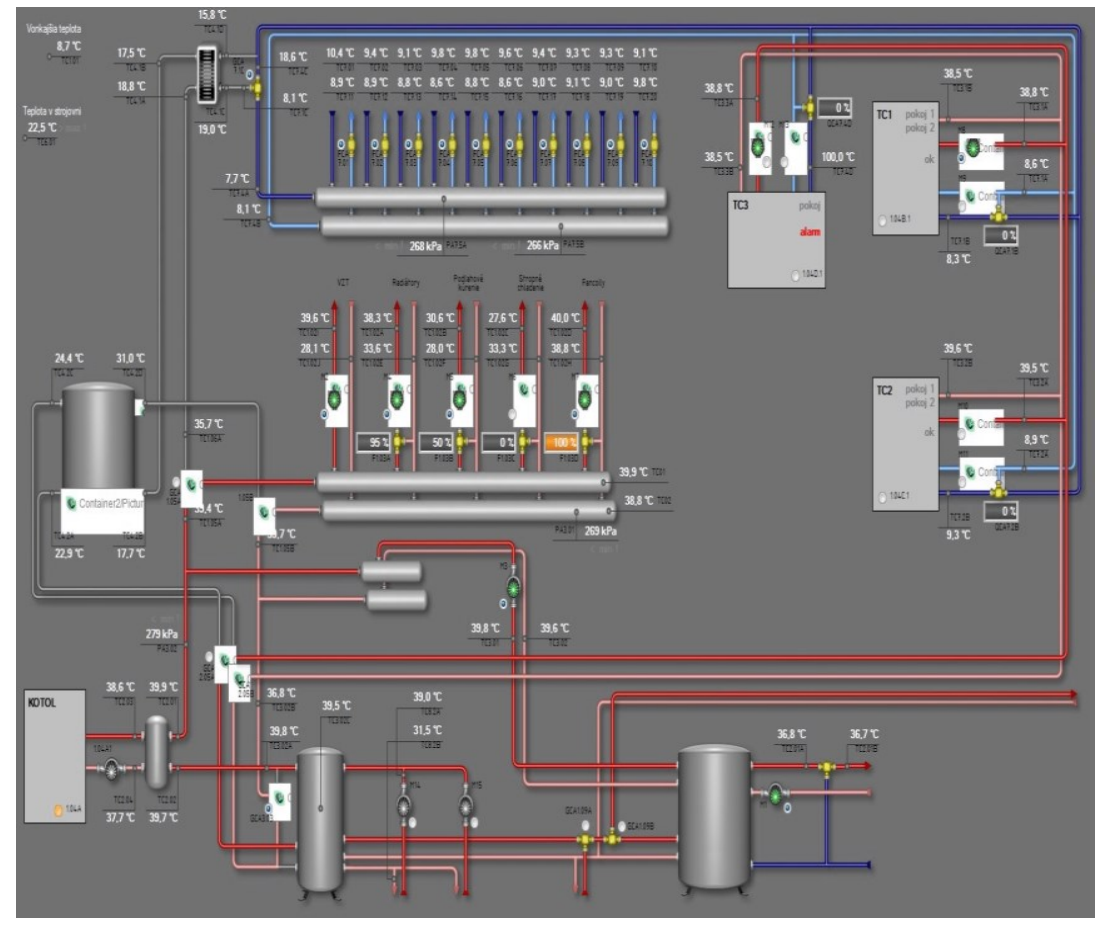

Fig. 4. Control in the technical room.

Our climatic conditions do not allow designers to use only one type of renewable energy source. The combination of several types of energy sources must be used to provide the necessary energy. Currently, the building is set to heat by electric heat pumps. In case of higher energy consumption, the gas condensing boiler is used. The solar system is primarily designed for hot water heating. In the next step, it charges the storage tank. After securing these features, it is used to charge the ground thermal storage. In this case, the heat is deposited with a volume of $770 \mathrm{~m}^{3}$ in the rock.

Ground thermal storage has three heating wells with water. Heating is provided via the solar system. The rock is heated by the wells and the heat accumulates during the summer. Ground thermal storage has earth needles that serve to recover heat in the winter. The perimeter walls and the top wall are insulated. The bottom wall is not. The location of the thermal ground storage is on the subsoil, which can isolate itself, or losses to the environment are acceptable. If the temperature falls below $17{ }^{\circ} \mathrm{C}$ for 2 hours, the heat pumps will automatically switch on - heating mode. If the temperature is more than $20{ }^{\circ} \mathrm{C}$ 2 hours, the cooling mode switches.

The cooling ceiling system is used for cooling. The laboratories also have air conditioning units to ensure an optimal operating environment. Ventilation is controlled by air breathing sensors in every rooms. 
The control of the ventilation is individual for each floor, because the first floor contains chemical laboratories and the offices are on the other floors (Figure 5).
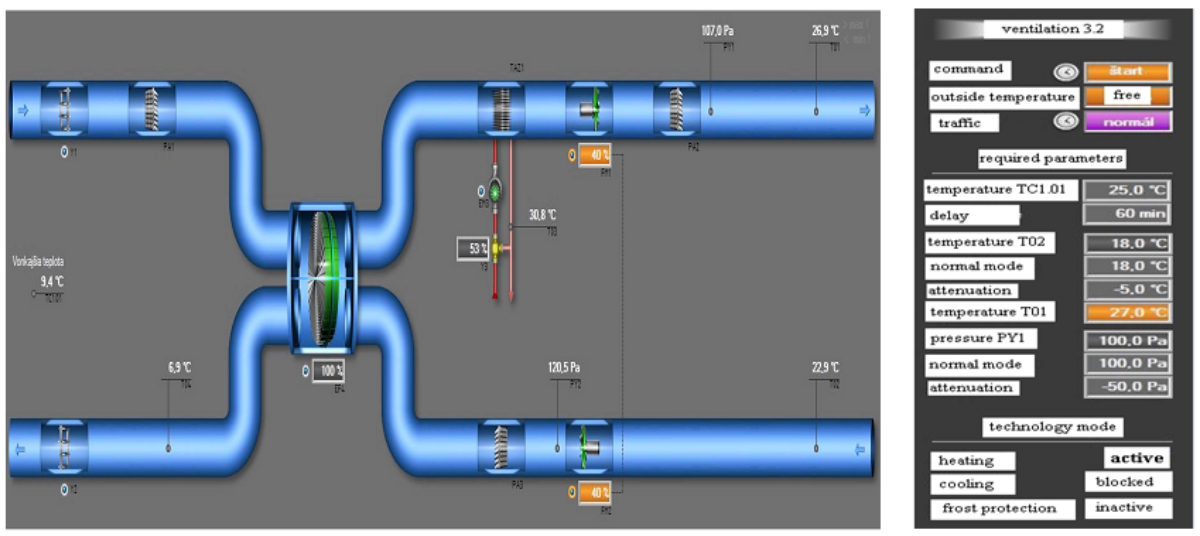

Fig. 5. Control and monitoring system for ventilation.

\section{Conclusion}

Our aim is to create conditions for the implementation of applied research in the field of low-energy construction and technology for the construction of low-energy buildings, highefficiency energy sources using renewable energy sources and fossil fuels, the optimal control, optimal control of energy consumption in buildings and premises suitable choice of hot and cold sources, ensuring optimum energy consumption, safety and comfort in intelligent passive buildings, reducing the emission load environment.

Our main priority is to establish a functioning, modern system and achieving economic, environmental and proper functioning of several systems. Information on the possibility of heat accumulation in the ground thermal storage will be very interesting from an energy and economic point of view. Currently, we are working on optimizing the management program, which still needs certain programmatic corrections. We solve and eliminate problems with synchronization of individual technologies.

The research is supported by the European Structural Funds - project ITMS: 26220220121 (50\%) and KEGA 046ŽU-4/2016 "Unconventional systems using renewable energy".

\section{References}

1. S. Wang, Intelligent Buildings and Buildings Automation 64 (2009)

2. D. Clements-Croome, Intelligent buildings: An introduction (2011)

3. M. Jobb, L. Kosa, R. Nosek, M. Malcho, AEaNMiFMaE (2016)

4. B. Garlík, Inteligentní budovy (2012)

5. S. Števo, Čo tvorí inteligenciu budov? (2012)

6. R. Lenhard, T. Puchor, EPJ Web of Conferences, 143 (2017)

7. P. Nemec, M. Smitka, M. Malcho, Scientific world journal, 2014 (2014)

8. P. Nemec, M. Malcho, J. Jandačka, AIP Conference Proceedings, 1558 (2013) 